\title{
TRANSMISIÓN INALÁMBRICA DE SEÑALES MEDIANTE EL ESPECTRO DE LUZ VISIBLE
}

\section{Alvaro Riva y Omar Ormachea}

\section{RESUMEN}

Se presenta el desarrollo de un prototipo de comunicación inalámbrica de señales mediante el uso del espectro de luz visible con un ancho de banda de $5 \mathrm{MHz}$ (aproximadamente $80 \mathrm{Mbps}$ ) y una distancia de $15 \mathrm{~cm}$, el sistema desarrollado permite la transmisión de señales de audio \& video de forma inalámbrica mediante un LED (luz blanca). La luz que emite un diodo emisor, se encuentra dentro del espectro electromagnético de luz visible (400$700 \mathrm{~nm}$.), en este rango espectral, se tiene un potencial de ancho de banda de aproximadamente $322 \mathrm{THz}$, mucho mayor al que se usa en la transmisión de datos inalámbricos mediante ondas electromagnéticas de radio frecuencia (5 MHz para la tecnología 3G). Se instalaron todos los componentes electrónicos en placas impresas dentro de armazones para su uso de forma sencilla. El sistema funciona con fuentes de voltaje simétricas de +9, -9 voltios. El diseño final consta de un transmisor y un receptor de video. El sistema permite variar la intensidad del LED y de esta forma aumentar o reducir la distancia de transmisión; asimismo, es posible regular la ganancia tanto en el transmisor como en el receptor y, por último, se tiene una etapa sumadora y restadora en el transmisor y receptor, respectivamente, para efectivizar la calidad de transmisión de la señal. El sistema tiene un costo menor en un $80 \%$ en comparación con sistemas de transmisión de señales por luz visible comerciales.

Palabras Clave: Comunicación por Luz Visible, Espectro Electromagnético, Radiofrecuencia, LED, Ancho de Banda. 